\title{
Correction to: Advances in anesthesia technology are improving patient care, but many challenges remain
}

D. John Doyle ${ }^{1,2^{*}}$, Ashraf A. Dahaba ${ }^{3}$ and Yannick LeManach ${ }^{4,5}$

\section{Correction}

Unfortunately, after publication of this article [1], it was noticed that the name of Ashraf A. Dahaba is incorrectly displayed as Ashraf Dahaba. The full, corrected author list can be seen here. The original article was corrected.

\begin{abstract}
Author details
${ }^{1}$ Cleveland Clinic Lerner College of Medicine of Case Western Reserve University, Cleveland, Ohio, USA. 'Department of General Anesthesiology, Cleveland Clinic Abu Dhabi, Abu Dhabi, UAE, PO Box 112412, Abu Dhabi, UAE. ${ }^{3}$ Priv.-Doz. Dr.med.university, Division of General Anaesthesiology, Emergency- and Intensive Care Medicine, Medical University of Graz, Graz, Austria. ${ }^{4}$ Departments of Anesthesia and Health Research Methods, Evidence, and Impact, Michael DeGroote School of Medicine, Faculty of Health Sciences, McMaster University, 1280 Main Street West Hamilton, Hamilton, ON L8S 4L8, Canada. ${ }^{5}$ Population Health Research Institute, David Braley Cardiac, Vascular and Stroke Research Institute, Perioperative Medicine and Surgical Research Unit, 237 Barton Street East, Hamilton, ON L8L 2X2, Canada.
\end{abstract}

Published online: 30 May 2018

\section{Reference}

1. John Doyle D, Dahaba A, LeManach Y. Advances in anesthesia technology are improving patient care, but many challenges remain. BMC Anesthesiology. 2018;18:39. https://doi.org/10.1186/s12871-018-0504-X.

\footnotetext{
* Correspondence: djdoyle@hotmail.com

${ }^{1}$ Cleveland Clinic Lerner College of Medicine of Case Western Reserve University, Cleveland, Ohio, USA

${ }^{2}$ Department of General Anesthesiology, Cleveland Clinic Abu Dhabi, Abu

Dhabi, UAE, PO Box 112412, Abu Dhabi, UAE

Full list of author information is available at the end of the article
}

(c) The Author(s). 2018 Open Access This article is distributed under the terms of the Creative Commons Attribution 4.0 International License (http://creativecommons.org/licenses/by/4.0/), which permits unrestricted use, distribution, and reproduction in any medium, provided you give appropriate credit to the original author(s) and the source, provide a link to the Creative Commons license, and indicate if changes were made. The Creative Commons Public Domain Dedication waiver (http://creativecommons.org/publicdomain/zero/1.0/) applies to the data made available in this article, unless otherwise stated. 